Special Issue of the 8th International Advances in Applied Physics and Materials Science Congress (APMAS 2018)

\title{
Investigation of the Effects of Additives on Mechanical Properties of E-Glass Reinforced Thermoset Composites
}

\author{
F. ÖZGÜL AND N.B. BEKTAŠ* \\ Pamukkale University, Department of Mechanical Engineering, Denizli, Turkey
}

\begin{abstract}
Thermoset composites have a wide range of applications in the automotive, defense and aerospace industries. The development of strength and mechanical properties of composites is very important. In this work, two different additives as ceramic nanoclay and polyamide powders were added to E-glass reinforced epoxy resin composites in various weights $0.5 \mathrm{wt} \%, 1.0 \mathrm{wt} \%$ and $2.0 \mathrm{wt} \%$. The effects of additives on the mechanical properties of composites were determined experimentally. In addition, mixtures of these additives were also used and the efficacy of each was compared. The positive effects of additives were observed. As a result, it was found that the tensile, buckling and compressive strengths of composites increased significantly.
\end{abstract}

DOI: 10.12693/APhysPolA.135.915

PACS/topics: epoxy, E-glass, composite, additives, mechanical properties

\section{Introduction}

Epoxy resins, which are the most important class of thermoset polymers, are widely used in structural applications, automotive, defense and aerospace industries, due to their superior mechanical, thermal and electrical properties. In all these applications, however, epoxy resins are fragile and rigid in nature and have poor resistance to crack propagation which limit their use in most applications. Recent studies have shown that combination of nanometer-sized additives or fillers with polymer matrices results in efforts to improve the properties of the polymer. Polymer matrix embedded nanoparticles; is a rising trend due to unique mechanical, optical, electrical and magnetic properties when compared to pure polymers [1-4].

In this study, the effects of ceramic nanoclay and polyamide powder additives on the mechanical properties of GFRP composites were investigated experimentally. In determining the mechanical properties, the tensile test, compression test and buckling test were carried out according to the ASTM standards. Ten types of matrix compositions such as pure epoxy named as Pure, polyamide powder/epoxy (0.5 wt\%, $1.0 \mathrm{wt} \%$ and $2.0 \mathrm{wt} \%$ ) named as PA, nanoclay/epoxy (0.5 wt\%, $1.0 \mathrm{wt} \%$ and $2.0 \mathrm{wt} \%)$ named as $\mathrm{NC}$ and polyamide + nanoclay/epoxy $(1.0+1.0 \mathrm{wt} \%)$ named as PC were used in manufacturing of GFRP composites.

\section{Experimental procedure}

Materials used were glass fiber reinforced composites based on epoxy resin. Epoxy resin was a standard diglycidyl ether of bisphenol A (DGEBA) and Araldite

\footnotetext{
*corresponding author; e-mail: nbbektas@pau.edu.tr
}

The physical properties of additives.

TABLE I

\begin{tabular}{l|l|c|c|c}
\hline \hline Additives & Description & $\begin{array}{c}\text { Density } \\
{\left[\mathrm{g} / \mathrm{cm}^{3}\right]}\end{array}$ & $\begin{array}{c}\text { Particle } \\
\text { size }\end{array}$ & Color \\
\hline $\begin{array}{l}\text { ceramic } \\
\text { clay }\end{array}$ & $\begin{array}{l}\text { organic } \\
\text { intercalated } \\
\text { nanoclay }\end{array}$ & 1.77 & $\begin{array}{c}<10 \mu \mathrm{m}\left(d_{50}\right) \\
3.16 \mathrm{~nm}\left(d_{001}\right)\end{array}$ & off white \\
\hline polyamide & $\begin{array}{l}\text { spheroidal } \\
\text { powder }\end{array}$ & 0.375 & $30 \mu \mathrm{m}$ & white
\end{tabular}
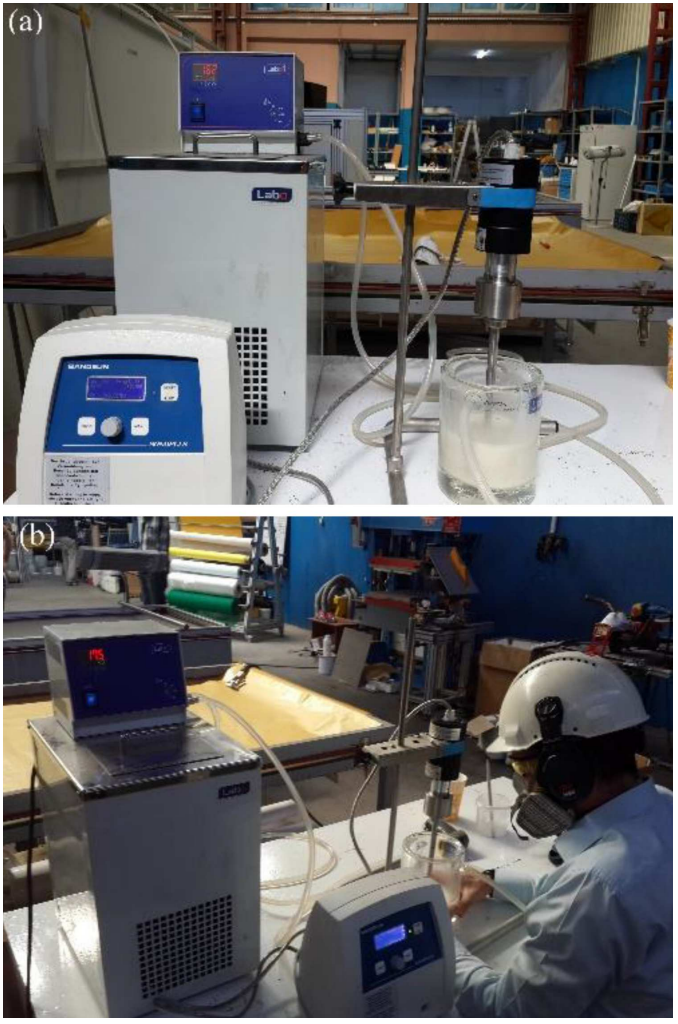

Fig. 1. (a) cooling system, (b) additives homogenization. 

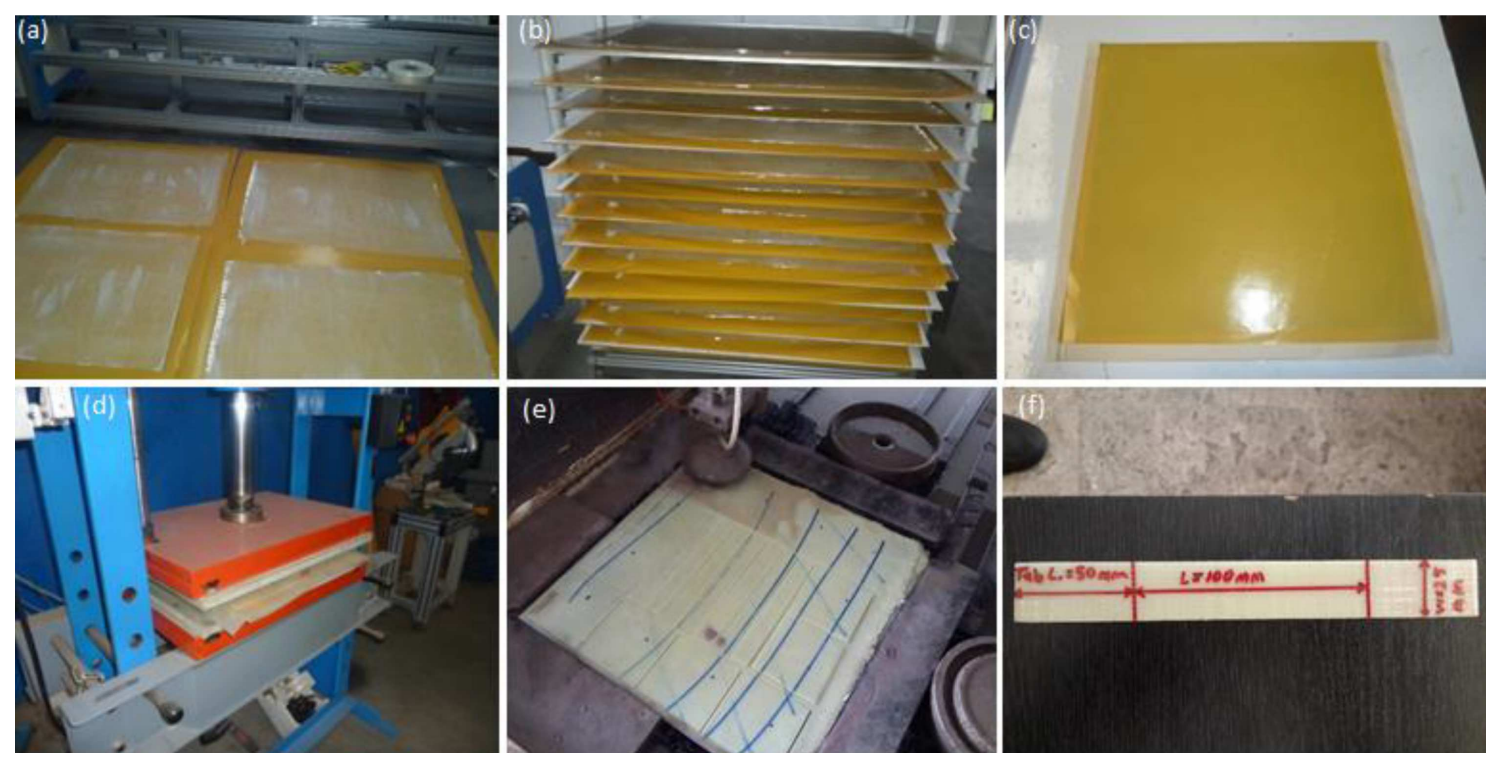

Fig. 2. Manufacturing of composites; (a) resin impregnation, (b) impregnated prepregs resting, (c) waxed plates (d) hot pressed and cured, (e) cutting with water jet, (f) test specimen.

LY 1564 supplied by Huntsman, Switzerland. E-glass fibre fabric was a woven fabric $0 / 90^{\circ}$ pattern with an areal weight of $300 \mathrm{~g} / \mathrm{m}^{2}$ from Huntsman, Switzerland. Ceramic nanoclay material composition is bis dimethyl (dihydrogenated tallow alkyl dimethyl), salt with bentonite. Nanoclay particle size is less than $10 \mu \mathrm{m}$ and polyamide powders average diameter is $30 \mu \mathrm{m}$. Ceramic nanoclay was provided by BYK-Chemie GmbH, from Wesel, Germany and polyamide powders were provided by Grolman GmbH, from Neuss, Germany. The physical properties of additives used are given in Table I.

Composites used were produced with prepreg technique. To improve the mechanical properties of composites, additives were dispersed homogeneously in epoxy resin. Otherwise, additives are dispersed nonhomogeneously and this causes stress concentrations effects to surface defects which is the main cause of fracture [5]. Therefore, additives were mixed in epoxy resin by using a sonicator which mixes the particles by emitting ultrasonic waves. The additives were weighed on a precision scale at $0.5 \mathrm{wt} \%, 1.0 \mathrm{wt} \%$ and $2.0 \mathrm{wt} \%$ by weight and added into the resin. The mixture of additives and epoxy resin were sonicated for 30 minutes at the temperature of $30^{\circ} \mathrm{C}$ by using Bandelin sonicator and cooling system, as shown in Fig. 1a and b.

Epoxy resin impregnated glass fabrics were left in wet gel for a period of time to mature. Composite materials were manufactured with glass fiber fabrics $\left(300 \mathrm{~g} / \mathrm{m}^{2}\right.$ in density) and pure epoxy resin and epoxy resin with additives of polyamide (0.5 wt \%, $1.0 \mathrm{wt} \%, 2.0 \mathrm{wt} \%)$, additives of nanoclay $(0.5 \mathrm{wt} \%, 1.0 \mathrm{wt} \%, 2.0 \mathrm{wt} \%)$ and additives of polyamide plus nanoclay $(1.0+1.0 \mathrm{wt} \%)$. Firstly, prepreg fabrics were prepared and left on the racks for three days to form a smooth interface free of air bubbles, as seen in Fig. 2a and b. The waxed papers were used to prevent sticking of press jaws, as seen in Fig. 2c. Prepreg fabrics covered with wrapping papers were hot pressed in 5 bar pressure and $120^{\circ} \mathrm{C}$ temperature and cured for 2 hours, as seen in Fig. 2d. Plates were slowly cooled to room temperature to avoid thermal distortions and stress concentrations, then the pressure was removed. After manufacturing of composite plates, they were cut in the form of test specimens by water jet, as seen in Fig. 2e and $\mathrm{f}$.

Test specimens were cut from composite plates manufactured in size of $400 \times 400 \mathrm{~mm}$. Tensile tests, compressive tests and buckling tests were carried out by using Instron 8801 model Servohydrolic Testing Machine as seen in Fig. 3a. In Fig. 3b the mechanical testing of a composite specimen is shown.

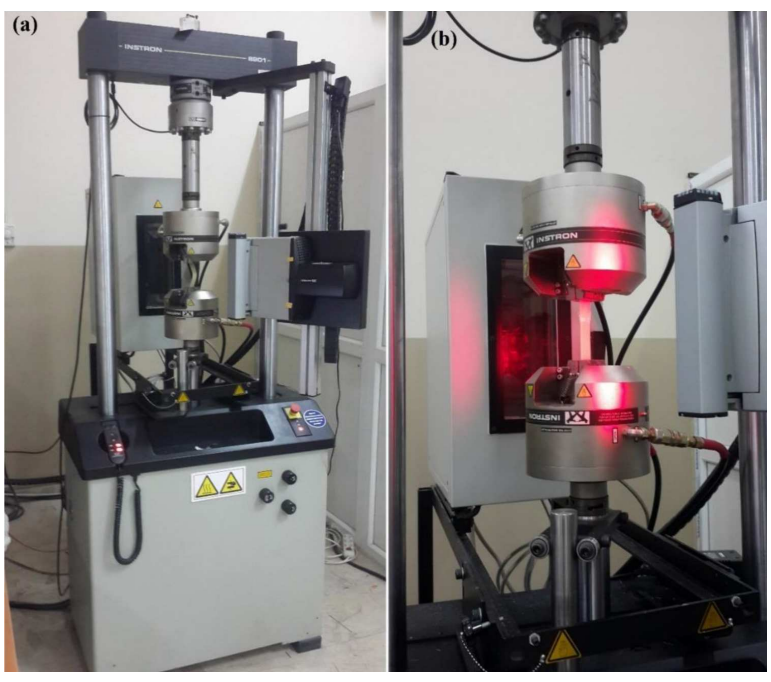

Fig. 3. (a) test equipment, Instron 8801, (b) mechanical testing of a composite specimen. 
All tests were carried out in the Mechanical Research Laboratory of Pamukkale University Department of Mechanical Engineering using the Instron 8801 model test machine. Test specimens were tested at a constant speed of $0.5 \mathrm{~mm} / \mathrm{min}$. For each composite type, at least three identical specimens were tested, the average test results reported and graphed in Figs. 4-6. All tests were carried out at room temperature under standard conditions.
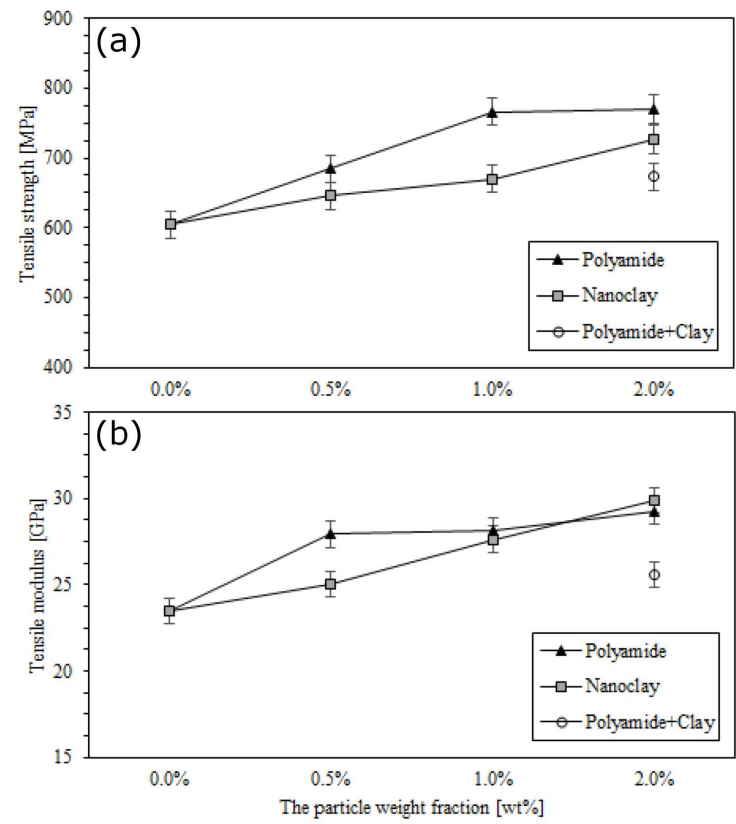

Fig. 4. The relationship of tensile test results to particle weight fractions for different types of additives:

(a) tensile strength, (b) tensile modulus.

Tensile tests were performed according to the ASTM D3039 standard [6] with computer-controlled servo-hydraulic tensile test machine. Axial strains were measured by video extensometer mounted on the test machine. Compressive tests were performed according to the ASTM D3410 standard [7] with computer-controlled servo-hydraulic compressive test machine. The critical buckling loads of pure and filled E-glass/epoxy composites were determined experimentally by applying compression loads using Instron 8801 tensile-compression testing machine.

\section{Results and discussion}

Results obtained from tensile tests were presented in Fig. 4. Addition of polyamide and nanoclay additives were affected positively to the tensile strength of composites.

From Fig. 4a, the tensile strength of composite specimens were increased from $604 \mathrm{MPa}$ to $770 \mathrm{MPa}$ with addition $2.0 \mathrm{wt} \%$ of polyamide and also increased up to $726 \mathrm{MPa}$ with addition $2.0 \mathrm{wt} \%$ of nanoclay. Finally, it increased to $672 \mathrm{MPa}$ with addition $1.0 \mathrm{wt} \%$ same amount of polyamide + nanoclay additives. Elasticity
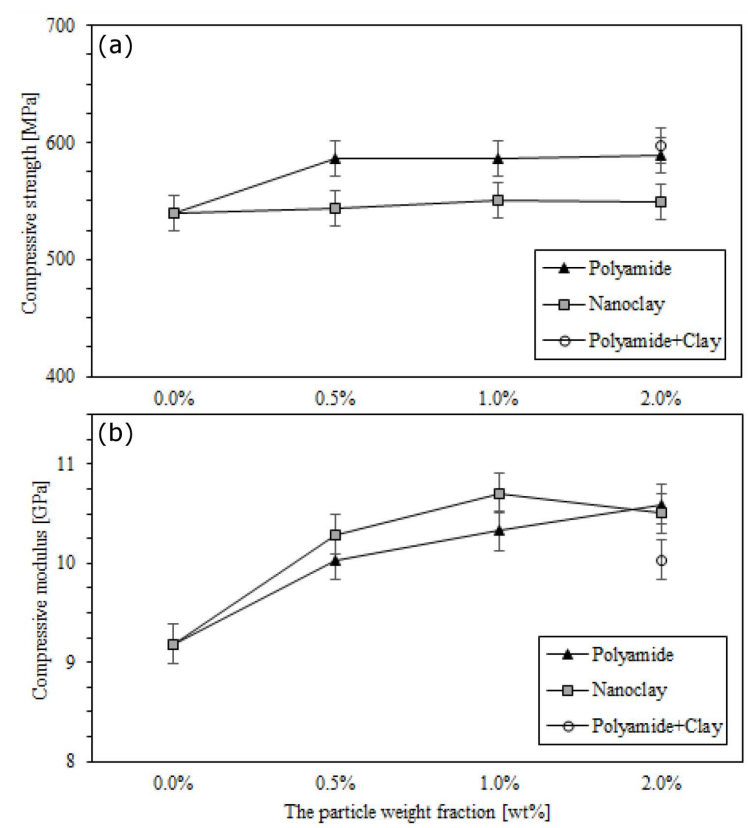

Fig. 5. The relationship of compressive test results to particle weight fractions for different additive types: (a) compressive strength, (b) compressive modulus.
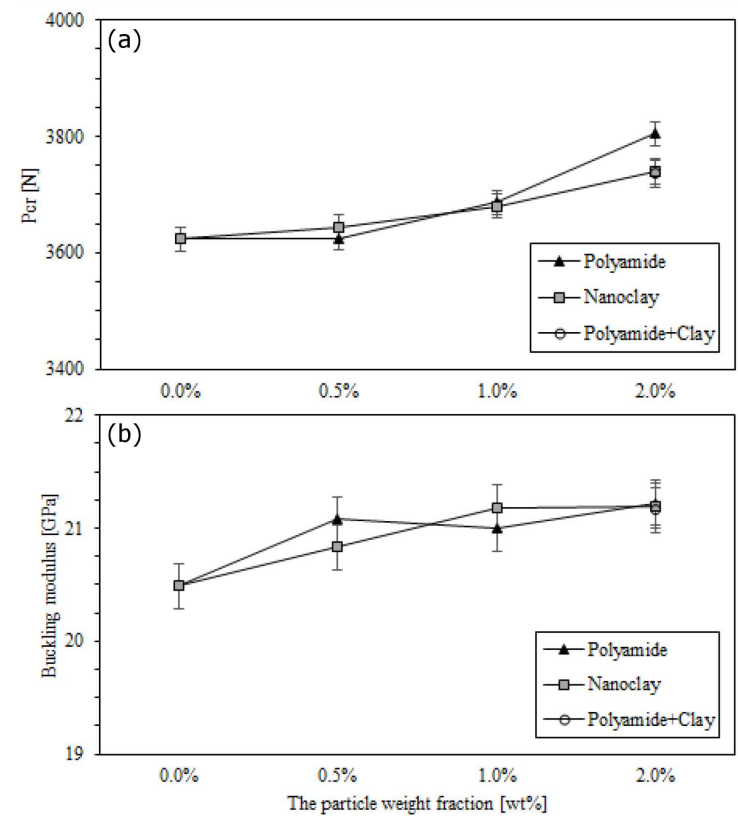

Fig. 6. The relationship of experimental buckling test results against particle weight fractions for different additive types: (a) critical buckling loads, (b) buckling modulus.

moduli of composite specimens increase from $23 \mathrm{GPa}$ to $29 \mathrm{GPa}$ with addition $2.0 \mathrm{wt} \%$ of polyamide and similar increasing with addition 2.0 wt\% of nanoclay, as seen in Fig. 4b.

Compressive test results obtained are shown in Fig. 5. All additives increased the compressive strength of GFRP composites. 
From Fig. 5a, the compressive strength of composite specimens were increased from $540 \mathrm{MPa}$ to $588 \mathrm{MPa}$ with addition $2.0 \mathrm{wt} \%$ of polyamide and also increased up to $549 \mathrm{MPa}$ with addition $2.0 \mathrm{wt} \%$ of nanoclay. Finally, it increased to $596 \mathrm{MPa}$ with addition $1.0 \mathrm{wt} \%$ same amount of polyamide + nanoclay additives. The presence of additives increased compressive modulus of composite specimens from $9 \mathrm{GPa}$ to $10 \mathrm{GPa}$, as seen in Fig. $5 \mathrm{~b}$.

Buckling test results obtained are shown in Fig. 6. For all additives enhancement of GFRP composites improve the buckling strength slightly.

From Fig. 6a, the critical buckling load of composite specimens were increased from $3623 \mathrm{~N}$ to $3804 \mathrm{~N}$ with addition $2.0 \mathrm{wt} \%$ of polyamide and also increased up to $3738 \mathrm{~N}$ with addition $2.0 \mathrm{wt} \%$ of nanoclay. Finally, it increased to $3737 \mathrm{~N}$ with addition $1.0 \mathrm{wt} \%$ same amount of polyamide + nanoclay additives. Addition of polyamide and nanoclay were affected positively on the strength of composites. The presence of additives increased buckling modulus of composite specimens from $20 \mathrm{GPa}$ to $21 \mathrm{GPa}$, as seen in Fig. 6 b.

\section{Conclusion}

In this study, the effects of additives in epoxy matrix on the mechanical properties of glass fiber composites have been investigated experimentally.

The tensile strength increased by about $27 \%, 20 \%$ and $11 \%$, while the modulus of the polyamide, nanoclay and polyamide/nanoclay filled GFRP composites increased by about $24 \%, 27 \%$ and $9 \%$ respectively.

The compressive strength increased by about $9 \%, 2 \%$ and $10 \%$, while the modulus of the polyamide, nanoclay and polyamide/nanoclay filled GFRP composites increased by about $15 \%, 16 \%$ and $9 \%$, respectively.

The buckling load increased by about 5\%, 3\% and $3 \%$, while the modulus of the polyamide, nanoclay and polyamide/nanoclay filled GFRP composites increased by about $3 \%$ respectively.
Composite materials produced by adding $2.0 \mathrm{wt} \%$ polyamide showed a $27 \%$ improvement in tensile strength and a $24 \%$ improvement in tensile modulus. With addition of $1.0 \mathrm{wt} \%$ polyamide plus nanoclay were showed $10 \%$ improvement in compressive strength and $9 \%$ improvement in compressive modulus. Also with addition of $2.0 \mathrm{wt} \%$ polyamide were showed $5 \%$ improvement in buckling strength and $3 \%$ improvement in buckling modulus.

\section{Acknowledgments}

The authors would like to thank BAP (Scientific Research Project Fund of Pamukkale University) for supporting this study under project number 2017FEBE049.

\section{References}

[1] M. Sayer, N.B. Bektaş, E. Demir, H. Çallığlu, Composites: Part B 43, 2152 (2012).

[2] A. Mirmohseni, S. Zavareh, Materials and Design 31, 2699 (2010).

[3] D.K. Shukla, S.V. Kasisomayajula, V. Patameswaran, Composites Science and Technology 68, 3055 (2008).

[4] M.M. Shokrieh, A.R. Kefayati, M. Chitsazzadeh, Materials and Design 40, 443 (2012).

[5] K.T. Gürsel, F. Özgül, Materialwissenschaft und Werkstofftechnik 45, 26 (2014).

[6] ASTM D3039/D3039M-17, Standard Test Method for Tensile Properties of Polymer Matrix Composite Materials, ASTM International, West Conshohocken (PA) 2017.

[7] ASTM D3410/D3410M-16, Standard Test Method for Compressive Properties of Polymer Matrix Composite Materials with Unsupported Gage Section by Shear Loading, ASTM International, West Conshohocken (PA) 2016. 